\title{
PROgRESS-ORIENTED WORKSHOPS FOR DOCTORAL WELL-BEING: EVIDENCE FROM A TWO-COUNTRY DESIGN-BASED RESEARCH
}

\begin{tabular}{lll}
\hline $\begin{array}{l}\text { Luis P. Prieto } * \\
\text { Paula Odriozola-González }\end{array}$ & $\begin{array}{l}\text { Tallinn University, Tallinn, Estonia } \\
\text { Universidad de Cantabria, Santander, } \\
\text { Spain }\end{array}$ & $\begin{array}{l}\text { lprisan@,tlu.ee } \\
\text { paula.odriozola@,unican.es }\end{array}$ \\
$\begin{array}{l}\text { María Jesús Rodríguez- } \\
\text { Triana }\end{array}$ & Tallinn University, Tallinn, Estonia & $\underline{\text { mirt@,tlu.ee }}$ \\
Yannis Dimitriadis & $\begin{array}{l}\text { Universidad de Valladolid, Valladolid, } \\
\text { Spain }\end{array}$ & $\underline{\text { vannis@,tel.uva.es }}$ \\
Tobias Ley & Tallinn University, Tallinn, Estonia & $\underline{\text { tley@,tlu.ee }}$
\end{tabular}

* Corresponding author

\begin{abstract}
Aim/Purpose

This paper explores an intervention approach (in the form of workshops) focusing on doctoral progress, to address the problems of low emotional wellbeing experienced by many doctoral candidates.

Background Doctoral education suffers from two severe overlapping problems: high dropout rates and widespread low emotional well-being (e.g., depression or anxiety symptoms). Yet, there are few interventional approaches specifically designed to address them in the doctoral student population. Among structural, psychosocial and demographic factors influencing these problems, the self-perception of progress has emerged recently as a crucial motivational factor in doctoral persistence.
\end{abstract}

Methodology This paper reports on an iterative design-based research study of workshop interventions to foster such perception of progress in doctoral students' everyday practice. We gathered mixed data over four iterations, with a total of $\mathrm{N}=82$ doctoral students from multiple disciplines in Spain and Estonia.

Contribution An approach to preventive interventions that combines research-backed education about mental health and productivity, peer sharing and discussion of experiences and indicators of progress, as well as self-tracking, analysis and reflection upon everyday evidence of their own progress. The paper provides initial evidence of the effectiveness of the proposed interventions, across two institutions in two different countries. Further, our data confirms emergent research on the relationships among progress, emotional well-being and dropout ideation in two new contexts. Finally, the paper also distils design knowledge about doctoral interventions that focus on progress, relevant for doctoral trainers, institutions and researchers.

Findings Our quantitative and qualitative results confirm previous findings on the relationships among progress, burnout and dropout ideation. Our iterative evaluation of the workshops also revealed a large positive effect in students' positive psychological capital after the workshops (Cohen's $d=0.83$ ). Our quantitative and qualitative analyses also started teasing out individual factors in the variance of these benefits. 
Progress-Oriented Workshops for Doctoral Well-being

Recommendations Intervention design guidelines for doctoral trainers include: focusing on actionfor Practitioners able productivity and mental health practices, the use of activities targeting perception biases and taboos, or the use of active practices and real (anonymous) data from the participants to make progress visible and encourage reflection.

Recommendations The construct of progress, its components and its relationships with both emofor Researchers tional well-being and doctoral dropout, need to be more deeply studied, using multiple methods of data collection, especially from more frequent, ecologically valid data sources (e.g., diaries).

Impact on Society The proposed interventions (and focusing on doctoral progress more generally) hold promise to address the current emotional well-being and dropout challenges facing hundreds of thousands of doctoral students worldwide, ultimately helping increase the research and innovation potential of society as a whole.

Future Research

More rigorous evaluative studies of the proposed approach need to be conducted, with larger samples and in other countries/contexts. Aside from the proposed one-shot training events, complementary longitudinal interventions focusing on supporting everyday progress and reflection throughout the doctoral process should be trialed.

Keywords Doctoral education, emotional well-being, doctoral attrition, progress, designbased research, preventive intervention.

\section{INTRODUCTION}

Doctoral studies are one of the longest and most arduous learning processes humans engage in. The high attrition rates, which some studies estimate at 50\% (Bair \& Haworth, 2004; Wollast et al., 2018) and even higher for online studies (Terrell et al., 2012), make it a highly uncertain endeavor. Additionally, the high incidence of emotional disorders like stress, depression or anxiety, with an increasing prevalence now estimated at 30-50\% (Evans et al., 2018; Levecque et al., 2017), has recently led to warnings of a "mental health crisis" in doctoral education (Evans et al., 2018). Indeed, there is now evidence that these two phenomena (attrition and emotional distress) often overlap (GonzálezBetancor \& Dorta-González, 2020).

Multiple contextual factors seem to affect doctoral dropout rates and emotional well-being (Mackie \& Bates, 2018; Sverdlik et al., 2018): from structural/organizational issues (e.g., availability of funding, transparency of university processes), to the relationship with the supervisor or the individual's own personal situation (e.g., having children or a stable partner, or financial difficulties). Looking at process factors upon which students themselves have some degree of control, we can find lifestyle choices like the amount of sleep and exercise taken. More recently, the perception of one's own progress has been related to both doctoral persistence (Devos et al., 2017) and well-being (Milicev et al., 2020) - independently mirroring similar findings in organizational psychology (Amabile \& Kramer, 2011). However, the evidence for the importance of progress in doctoral attrition and emotional well-being is still emerging (often, from studies in a single country, institution and/or discipline). Furthermore, it is unclear how to foster $\mathrm{PhD}$ students' perception of progress and emotional wellbeing during the dissertation process, which is known to be highly unique and contextual (Sinclair, 2004).

This paper describes a design-based research (DBR, see Barab \& Squire, 2004; Cobb et al., 2003) aimed at the design of short, preventive, technology-enhanced doctoral training interventions to foster this sense of progress and thus improve the students' psychological resources to cope with the hardships of the PhD process. This DBR has been developed over a period of four semesters, in the context of two universities in different countries, with widely different local cultures (Estonia and 
Spain). Our goals are a) to confirm emergent research on the relationships among progress, emotional well-being and dropout ideation, in two new contexts; b) to evaluate the effectiveness of the designed interventions on students' resources for emotional well-being; and c) to provide design guidelines for interventions that foster doctoral progress and resources for emotional well-being.

Towards these aims, we have conducted so far five interventions (along four different format iterations), attended by a total of 82 doctoral students from different disciplines. The workshop formats included both face-to-face and online modalities (in part caused by the restrictions imposed during the recent COVID-19 pandemic). We have used mixed methods (Creswell, 2009) of data gathering, including questionnaires, observations, and student diary exercises. These data have, in turn, been analyzed using both quantitative and qualitative analysis methods to tackle the three goals outlined above in a triangulated fashion.

\section{RELATED WORK}

\section{DROPOUT AND EMOTIONAL WELL-BEING IN DOCTORAL STUDIES}

Doctoral studies suffer from high rates of students that either drop out (i.e., attrition, see Litalien \& Guay, 2015) or take too long to finish; different studies provide attrition rates of 40-60\% (Bair \& Haworth, 2004; Wollast et al., 2018), and up to $70 \%$ for online doctoral programs (Terrell et al., 2012). In parallel with this research on doctoral attrition, studies place the prevalence of emotional well-being problems like depression or anxiety among doctoral students around $40 \%$ (e.g., Evans et al., 2018; Levecque et al., 2017), higher than similar demographic groups (e.g., other higher education students and highly educated workforce, see Levecque et al. 2017). While more recent estimations of prevalence gave out lower numbers (24\% for depression, $17 \%$ for anxiety, see Satinsky et al., 2021), if we consider the global doctoral student population (Taylor, 2021), we can conclude that currently, more than half a million doctoral students may be suffering from such conditions worldwide (and double that number can be at risk of doctoral dropout).

While attrition and low emotional well-being are normally studied separately, recent research has shown that they largely overlap, with emotional well-being problems often involved in accounts of doctoral dropping out (González-Betancor \& Dorta-González, 2020; Liu et al., 2019). The long list of organizational, contextual and personal factors that research has related to these two problems (Litalien \& Guay, 2015; Smith et al., 2006; Sverdlik et al., 2018; Wollast et al., 2018) paints a bleak picture for prospective $\mathrm{PhD}$ students, who may have little agency over many of these variables. Correlates over which students may have more direct influence include (Bauer, 2016; Byrom et al., 2020; Marais et al., 2018; Myers et al., 2012; Richardson et al., 2020): everyday healthy habits like sleep schedule or exercise, perfectionist behaviors, mindful acceptance or cognitive reappraisal. However, the relative importance and relationships among these factors are still unclear.

The measurement of these two constructs (doctoral dropout and emotional well-being) is not trivial. Doctoral attrition has long been known to be difficult to measure, given the length of doctoral studies (ranging from a planned time of 3-4 years to a decade or more of actual time to completion). The lack of formal requirements of enrollment in the research phase of the dissertation, in many institutions, has lead doctoral programs to often take proxy measures (e.g., the number of semesters/years each student is taking to finish the dissertation). However, we often lack publicly available data about student attrition. Further, once it can be measured (i.e., the student has dropped out), it is often too late to intervene or support the affected doctoral student. Therefore, a commonly-used shorter-term proxy measure of attrition is dropout ideation (Litalien \& Guay, 2015; Peltonen et al., 2017; Hardre et al., 2019), often measured through a single-item question (e.g., Peltonen et al., 2017) or with instruments inspired in similar constructs like suicidal ideation (e.g., Posner et al., 2011).

Doctoral emotional well-being has been evaluated in doctoral populations through variables such as mental health, absence of anxiety, stress or depression symptoms, themselves measured with clinical- 
Progress-Oriented Workshops for Doctoral Well-being

ly-validated self-report instruments like the DASS-21, GHQ-12, PHQ-9 or GAD-7 (e.g., in Evans et al., 2018; Barry et al., 2019; Levecque et al., 2017; Marais et al., 2018). In addition, academic stress or burnout has been specially related, in the context of the doctorate, with emotional well-being problems (e.g., Sorrel et al., 2020) and intentions to drop out (Peltonen et al., 2017) or leave academia (Devine \& Hunter, 2016). In this sense, aside from generic burnout scales from organizational psychology, Cornér and colleagues at the University of Helsinki (2017) have developed an 8-item burnout scale specifically for doctoral student populations.

Given our desire to develop brief, cost-effective preventive interventions targeting a majority of (non-clinical) doctoral student populations, we also need to consider an alternative to measuring symptoms of low emotional well-being (which is what most of the instruments described above are designed for). In this sense, recent intervention studies to improve doctoral student well-being have focused on measuring the positive emotional resources that students tap into when facing emotional challenges (e.g., Barry et al., 2019). A common way to measure these resources is positive psychological capital (or PsyCap, see Luthans et al., 2007), which often is defined as having four subcomponents (hope, self-efficacy, resilience and optimism), usually measured through self-report questionnaires (e.g., Lorenz et al., 2016). PsyCap has been linked with many of the aforementioned constructs, like anxiety or well-being (see Luthans \& Youssef-Morgan, 2017 for an overview) as well as work performance and satisfaction (Luthans et al., 2007), which may itself be relevant for progress and eventual dissertation completion (see below).

\section{INTERVENTIONS FOR WELL-BEING AND DROPOUT IN DOCTORAL STUDIES}

In contrast with the wealth of research about prevalence and correlates of doctoral student attrition and emotional disorders (Marais et al., 2018; Sverdlik et al., 2018; Rockinson-Szapkiw, 2019), there is much less research on how to intervene in this state of affairs. A review in the context of higher education (Conley, 2015) pointed out that the evidence of the effectiveness of mental health-oriented interventions is still heterogeneous, but mentions that mindfulness-oriented approaches, and those that have a supervised practice component, seem to be most effective. A more recent review of interventions for doctoral mental health (Mackie \& Bates, 2018) found just five studies, some of which provide only anecdotal evidence of effectiveness (e.g., the stress management program in Smith et al., 2006). Another recent review of studies looking at early doctoral student mental health (Jackman et al., 2021) found only one interventional study targeting that population.

Only now we are starting to see intervention studies with stronger evidence, like the eight-week mindfulness program described by Barry and colleagues (2019), based on Kabat-Zinn's MBSR, which lowered depression symptoms and increased doctoral students' psychological capital. Another 8-week positive psychology intervention showed significant effects in doctoral student anxiety, in a smallsample, single-institution study ( $\mathrm{N}=23$ students, out of which only 10 took the intervention, see Marais et al., 2018). There have also been attempts at even shorter interventions (a single two-hour session) for graduate students using a cognitive-behavioral approach (Bernstein et al., 2020). As we can see, the dominant approach in this still-emergent area is to reuse/adapt approaches and programs designed for the general population. Further, research into doctoral students' acceptance of such interventions suggests that there may not be a "silver bullet" that addresses all emotional well-being problems in all students, and that individual differences and history need to be taken into account (Hish et al., 2020).

The problem of doctoral attrition, however, remains even harder to solve, with scarcer (sometimes, anecdotal) evidence of intervention effectiveness. The attrition interventions that we can find in the literature are often complex, wide-ranging programs like the "Dissertation Completion Grant Program" mentioned by Hanson and colleagues (2020), which had a budget of more than 6,000 US $\$$ per doctoral student; or the changing of a whole doctoral program to a "collaborative cohort model" to support completion (Colon, 2012); or the whole-program redesign described by McBrayer and colleagues (2018), which expedited time to completion but did not affect overall completion rates. 


\section{Progress as a CRUCIAL FACTOR IN Doctoral PERSISTENCE AND EMOTIONAL WELL-BEING}

Another factor that seems to play a role in both doctoral emotional well-being and attrition has emerged recently: the perception of one's own progress in the dissertation. A qualitative study of $\mathrm{N}=21$ doctoral students in Belgium uncovered that the main distinguishing aspect of candidates that completed their PhD was that, in their everyday experience, they were "progressing serenely in a project that makes sense", a theme that relates completion, meaning-making and mental distress (Devos et al., 2017). Independently, in a survey of $\mathrm{N}=479$ postgraduate students in the UK, researchers have also found significant negative correlations between doctoral students' perceptions of progress and well-being (Milicev et al., 2020). Similar results were found in another survey study of $N=81$ doctoral students in Australia, where students that self-reported being behind schedule also reported higher symptoms of anxiety, depression and stress (Barry et al., 2018). These studies in doctoral education inadvertently mirror prior research in organizational psychology (Amabile \& Kramer, 2011), suggesting that steady progress often leads to satisfaction and other positive emotions, which reinforce productive behaviors, in turn leading to more progress, thus establishing a virtuous "progress cycle".

\section{GAPS IN CURRENT RESEARCH}

Despite the increasing body of research on doctoral attrition and emotional well-being, several limitations can be found in the literature outlined above:

A. The evidence about the importance of progress in these phenomena is still emergent, normally from studies in a single country, institution or discipline (i.e., the generalizability and quality of those relationships are still unclear).

B. There exist few preventive interventions that address emotional well-being and attrition. Furthermore, existing intervention programs are generally cumbersome and/or expensive (especially regarding attrition), and have only been tested in single countries or institutions.

C. Given the limited number of interventions in the literature, we lack design knowledge to help doctoral-level trainers and institutions in designing effective interventions (for instance, focusing on progress as a critical concept) to address the aforementioned attrition and emotional well-being problems; and

D. Methodologically speaking, most of the studies mentioned above are either purely quantitative or purely qualitative, with triangulation of mixed methods as a way to enhance the credibility of research findings (Greene et al., 1989) still being rarely used.

Following calls to action by researchers about the need for including mental health issues in doctoral professional development actions (e.g., seminars, courses, see Sverdlik et al., 2020), we propose to design iteratively one such brief, relatively inexpensive intervention of practical relevance to higher education institutions. We also follow suggestions by Smith et al. (2006), to study progress in relation to both emotional well-being and dropout, aiming to tease out some of the interactive relationships among these three elements with mixed methods of data collection and analysis. Finally, we also aim to heed Hish and colleagues' (2020) advice to explore individual differences to understand how different students may benefit differently from such an intervention.

\section{METHODOLOGY}

Overall aims and methodology. Taking into account the research gaps outlined above, we set out to design preventive interventions for doctoral students, in coordination with the doctoral schools of two universities (medium-sized public universities in Estonia and Spain, see Context below), which had expressed concerns about both doctoral student completion rates and emotional well-being. Following prior research (as outlined above), the interventions would focus on the notion of progress and helping $\mathrm{PhD}$ students understand its importance and cultivation in everyday practice. We also aimed at 
deriving "humble theories" (in that they are domain-specific, see Cobb et al., 2003) of how to design such interventions, which could be used by the doctoral education community in other settings. This dual aim led to our choice of design-based research (DBR) as the overall methodological framework. DBR is a methodological approach that takes place in naturalistic settings, and aims both for local impact and theoretical output (Barab \& Squire, 2004). DBR often involves multiple dependent variables, which researchers try to characterize in all their complexity. Most importantly, DBR involves iteration and revision of the research design as researchers improve their understanding of the phenomenon under analysis (Barab \& Squire, 2004). It should be noted that DBR insights and results are context-bound, and do not seek generalizability beyond the original contexts studied. Our DBR methodology was approached from a pragmatic stance (or rather, as Greene and Hall would put it, a "dialectical pluralist" paradigm, see Mertens, 2012; Johnson, 2017), and hence we have mixed quantitative and qualitative methods of analysis (see below) from different paradigms in the hope to achieve a better understanding of doctoral progress and the impact of the interventions, from the synthesis of those analyses. More concretely, we have used a convergent-parallel (also known as concurrent triangulation, see Creswell, 2009) research design, in which quantitative and qualitative data have been gathered at the same time, analyzed in parallel, and their findings compared with each other. As we describe below, both the intervention and the data gathering designs evolved over several iterations which took place, back and forth, between the Estonian and Spanish contexts.

Research questions. Our overarching research question could be formulated as: "What are the characteristics of a workshop intervention aimed at improving doctoral well-being by focusing on the notion of progress?" Taking into account the still emergent nature of prior evidence about the importance of a sense of progress to doctoral mental health and completion (which has been gathered in other countries and institutions), and our dual aim of providing effective interventions in-context and useful intervention design knowledge, we defined three main research questions to be explored:

- RQ1: Is the perception of progress related to doctoral well-being and dropout?

- RQ2: Do the progress-oriented interventions improve participants' well-being?

- RQ3: How should we design interventions to foster doctoral progress?

Following an anticipatory data reduction process (Miles \& Huberman, 1994), we also defined several more concrete informative questions to focus the collection and analysis of data to be gathered from our two educational contexts (see Figure 1).

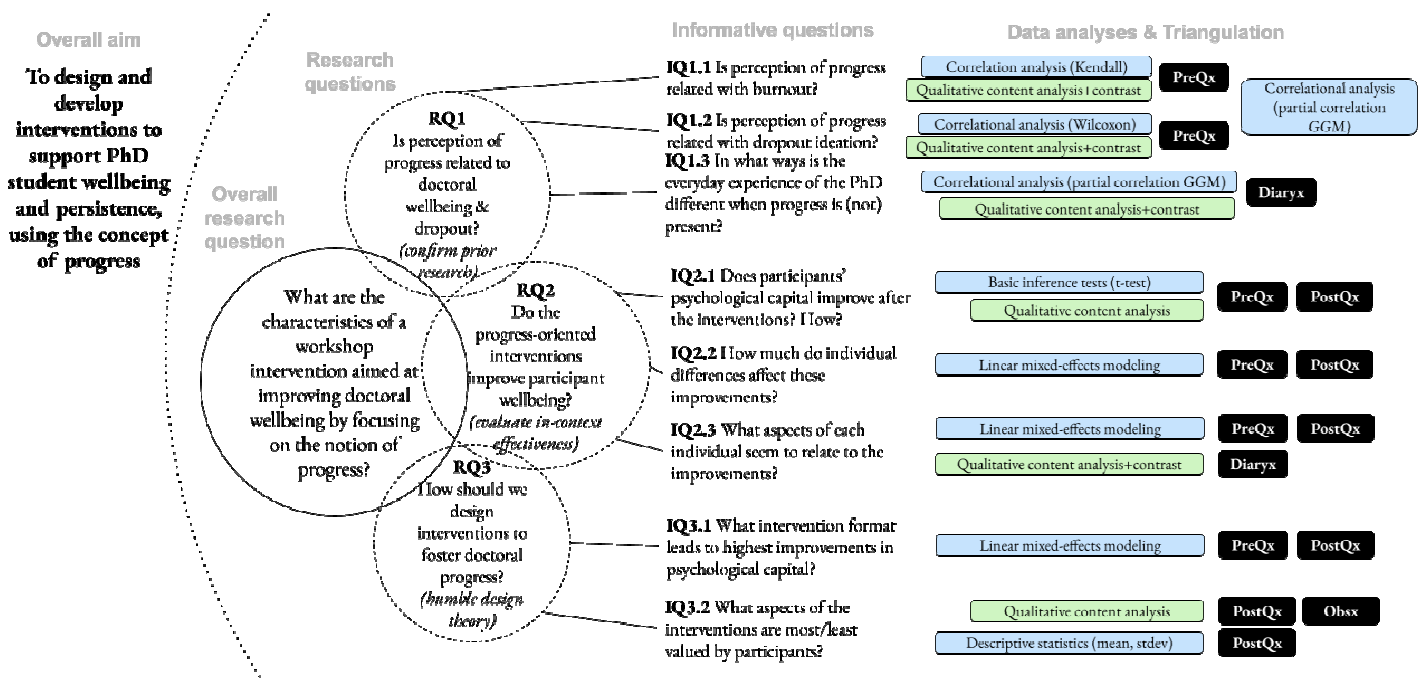

Figure 1. Research questions (RQx) and informative questions (IQx.x), and their relationship to the data gathering and data analysis techniques used during the DBR process. Co- 


\section{lored boxes denote different kinds of data analysis (green for qualitative, blue for quantita- tive). Black boxes indicate data sources used for the analysis (see Figure 3).}

Context. Our DBR took place across two European institutions (University of Valladolid - UVA, and Tallinn University, TLU), multi-disciplinary mid-sized public universities, one in Spain and another one in Estonia. These institutions were chosen due to the convenience of being the authors' own institutions (with easy access to the local doctoral schools), but they also offer a purposive sample of cultural and institutional extremes within the European spectrum: A long-established institution with more rigid and formalized doctoral processes in a Southern European culture, versus a relatively young university with doctoral rules and processes still in flux, in a post-Soviet Baltic country. In both cases, the doctoral schools had previously voiced concerns about the emotional well-being of doctoral students and the need for improving completion rates within the nominal time (3 years with a maximum cap of 5 years full-time at UVA; 4 years with a 6-year maximum cap at TLU). Thesis completion is indeed one of the key success indicators of doctoral schools (and, in Estonia, it even has an impact on the funding that the university receives from the State). While a majority of the doctoral students at UVA are of Spanish nationality (80\%) and develop a dissertation full-time (54\%), at TLU the proportion of international students is higher (25\%). It is worth noting that during the course of our DBR (spanning from the Autumn semester of 2019 to the Spring semester in 2021), the global COVID-19 pandemic forced a modification in both the students' working conditions (including the lockdowns of universities' premises, etc.) as well as the format of the workshop interventions themselves (which had to be held online from the third iteration onwards).

\section{Goals}

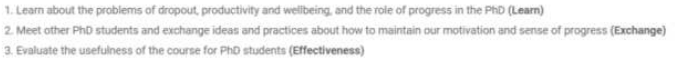

\section{Pre-course questionnaire}

\section{Activities}
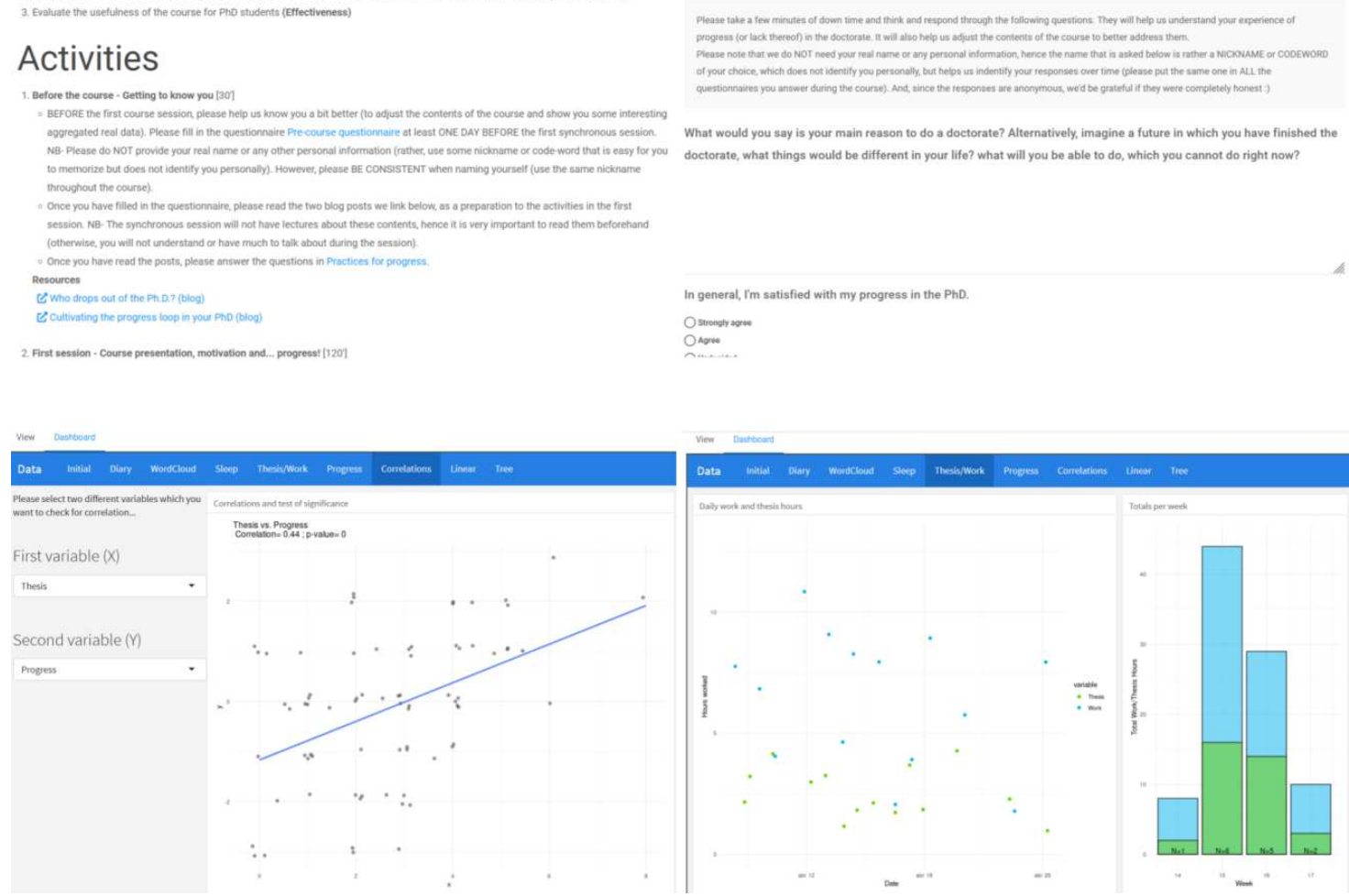

Figure 2. Screenshots of LAPills, the platform used for data collection and visualization by doctoral students. From top-left, clockwise: script guiding students through the activities and data collection in each workshop session; an example data gathering questionnaire; 
dashboard showing a temporal visualization of one of the variables recorded in the selftracking diaries; dashboard showing a visualization exploring correlations between data variables in the self-tracking diaries.

Intervention format and DBR iterations. We set out to design brief, preventive interventions to support doctoral students' perception of progress, hoping to improve their psychological resources to face the challenges of a $\mathrm{PhD}$ which often lead to attrition and emotional well-being issues. Another key feature of these interventions is that they are technology-enhanced, in particular, using studentfacing analytics (Bodily \& Verbert, 2017) of doctoral candidates' own real data, to illustrate the prevalence of these issues and enable reflection (inspired in the do-analyse-change-reflect pattern, see Kitto et al., 2017). The data collection and later visualization by doctoral students were supported using LAPills (https://web.htk.tlu.ee/lapills/), a simple open-source web platform designed to enable data collection and analysis by practitioners (see Figure 2).

As of this writing, we have conducted four iterations of our DBR, with both exploratory and evaluative aims (see Figure 3). A total of five interventions (workshops) have taken place: one per iteration, except for the last iteration which contained two workshops (with identical formats, one in each institution). The iterative evaluation outcomes, along with contextual factors (such as the lockdown measures in place in the Spring of 2020 due to the COVID-19 pandemic), led to an evolution in the workshop formats:

1. First iteration. A short face-to-face intervention (a single-session, two-hour workshop, see w1 in Figure 3) was trialed at TLU, focusing mainly on acquainting doctoral students with the importance of progress for doctoral persistence (see Related Work), the proposal of several practices to foster such progress in everyday doctoral work (e.g., journaling, self-tracking, making smaller goals), as well as practical collaborative exercises to understand what are concrete indicators of progress in different disciplines.

2. Second iteration. Following up on feedback from the first iteration (deemed too short by participants, see Results for a summary of evidence), a longer workshop was conducted in UVA (two sessions, two days apart, for a total of 6 contact hours and about one hour of independent student work, see w2 in Figure 3). This workshop incorporated additional modules introducing common mental health and productivity problems in the doctorate, potential solutions and practical individual and group exercises. The workshop also provided opportunities to perform a daily journaling/self-tracking practice using a simple web application (or pen and paper), during the two days between sessions.

3. Third iteration. Considering the feedback from the previous iterations (see Results) and the lockdown measures in place due to the COVID-19 pandemic, a third online workshop was carried out in the context of a biomedicine doctoral summer school, in the same public university in Spain (four sessions spanning three weeks, for a total of 6 contact hours and about two hours of independent student work, see w3 in Figure 3). The workshop used a "flipped classroom" structure (see Lo et al., 2017), in which individual readings and exercises were used to introduce some of the ideas before each contact session. The contents of this workshop variant were similar to those in the second iteration (which had good results in terms of increasing psychological capital and very positive participant feedback, see Results), although some of the exercises were modified to make them suitable and engaging in an online format. New group exercises were also added (a collaborative group activity to draw a "map of the doctorate" with important milestones and indicators of progress, in the students' particular discipline, as a way to foster students' sense of "appropriation" of their dissertation process) (see Devos et al., 2017).

4. Fourth iteration. Finally, two more online workshops (see w4 and w5 in Figure 3) were held for multi-disciplinary groups of students (one in Spain and another in Estonia). A flipped classroom format was again used and its contents were similar to those of the third iteration, but with longer sessions (two hours each), to enable more opportunities for discussion and shar- 
ing experiences with peers. Another innovation in this iteration was the visualization and reflection upon data from the ongoing journaling/self-tracking exercise (in aggregated and individual form), through an online data visualization dashboard (see Prieto et al., 2020 for examples of similar visualizations).

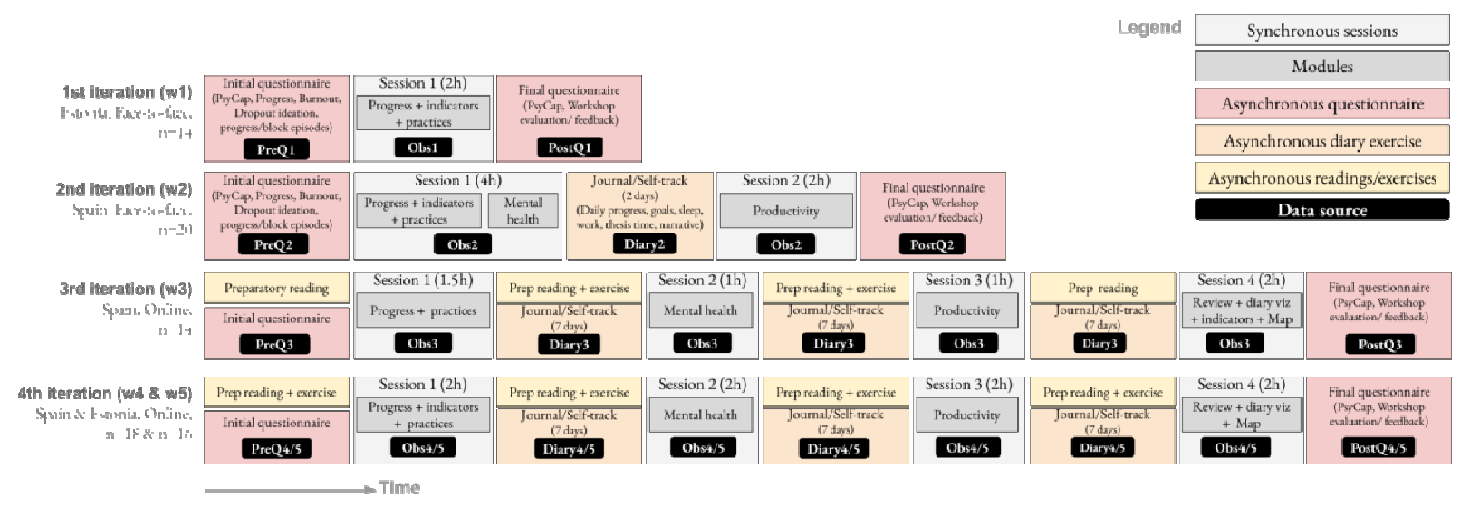

Figure 3. Intervention design and data collection events for the different iterations of the progress-focused workshops.

Participants. In all four iterations, the interventions were announced as usual elective courses by the respective doctoral schools, and participants enrolled on a voluntary basis. Doctoral students from multiple disciplines attended the first, second, fourth and fifth interventions $(\mathrm{N}=14,20,18$ and 16 students, respectively). $\mathrm{N}=14$ doctoral students from a biomedicine program attended the third one. The proportion of female students was $64 \%, 71 \%, 79 \%, 50 \%$ and $56 \%$, respectively. In the workshops held in Spain doctoral students were majoritarily of Spanish origin, while the workshops in Estonia had a more balanced mix of Estonian and foreign students. Doctoral students were in the middle stages of their doctorate, as students in the second or later years of doctorate were prioritized as workshop participants by the doctoral schools (and students in the final stage of the doctorate were unlikely to have found the topic of the workshops appealing).

Data gathering. Despite the changes in the workshop format, the mixed-methods data gathering performed in each iteration/workshop was largely the same, aiming at triangulating data sources to augment the validity of our answers to the research questions above:

- Pre-workshop questionnaires were used to gather data about the students' satisfaction with their own progress (Likert scale, range 1-5) and dropout ideation (yes/no). Furthermore, emotional well-being was measured using a doctoral burnout questionnaire (taken from a previous study in doctoral education, see Cornér et al. 2017) as well as positive psychological capital (PsyCap, see Luthans et al., 2007). PsyCap was chosen due to the interventions' preventive focus (i.e., rather than focusing on diminishing existing emotional well-being symptoms) and its use in prior research on doctoral well-being interventions (Barry et al., 2019). In particular, we used the CPC-12 instrument to measure PsyCap (see Lorenz et al., 2016). These initial questionnaires also gathered open responses about particular progress and blockage episodes and concrete indicators of progress that the students already used. In the second and later iterations, additional questions were posed regarding productivity strategies and challenges, as well as the occurrence of dropout ideation during the previous month. All questionnaires' data (and the diary entries, see below) were gathered anonymously, using a nickname to enable tracing of individual participants' data during the workshop, as well as more candid answers (given the sensitive and somewhat taboo nature of some of these questions, including, e.g., stigmatization of mental health problems, interpersonal or institutional conflict situations).

- The synchronous workshop sessions were observed (in an unstructured manner) by at least one member of the research team, to understand patterns of (dis)engagement with the for- 
Progress-Oriented Workshops for Doctoral Well-being

mat, and note suggestions and other remarks by the participants that might not be captured in the questionnaire data.

- During the second and later workshops, students were asked to follow two of the proposed practices for progress (journaling and quantitative self-tracking), in a voluntary and anonymous manner. These practices were facilitated through a simple web application that allowed inputting diary entries including both quantitative indicators (hours worked, hours worked in their own thesis project, hours slept, and satisfaction with the day's progress) and qualitative narratives of the events and accomplishments of the day, and goals for the next day.

- A post-workshop questionnaire was answered by the students to assess their levels of psychological capital after the event, and to evaluate different aspects of the workshop itself (e.g., clarity, adequacy of methods, perceived usefulness, etc.). Burnout or dropout intentions were not measured after the workshops, as it was deemed unlikely to have changed substantially during such a short intervention. The questionnaire also included open questions about especially strong or weak aspects of the workshop, and other comments and suggestions.

Data analysis. Following recommendations on DBR (Anderson \& Shattuck, 2012), we have used mixed methods of data analysis, triangulating them to increase the validity of our findings. In both quantitative and qualitative analyses, we have prioritized exploratory methods (rather than inferential ones trying to generalize beyond the context at hand):

- Given our lack of a prior detailed theory predicting the makeup and relations of the construct of progress and how it manifests in doctoral students' everyday experience, we coded the open responses in the pre- and post-questionnaires (and the narrative diary entries in the second and later workshops) using what Hsieh and Shannon (2005) would call an inductive, "conventional content analysis". Following an interpretative stance for this qualitative part of the analysis (i.e., recognizing researcher subjectivity and that knowledge is contextual, see Braun \& Clarke, 2019), one coder (the main author) labeled all entries and responses in a bottom-up fashion, developing a series of topics around them (e.g., kinds of progress or blockage episodes, emotions mentioned, changes in everyday practice stemming from the workshop, weak aspects in the workshop design, etc.). This coded dataset was then inquired upon from the standpoint of the different informative questions defined for each research question (see Figure 1), as described below. Nevertheless, it is worth noting that the coder's interpretations may have been influenced by his initial focus on emphasizing student agency (over, e.g., institutional or organizational factors), the belief in the importance of progress as a crucial construct to understand doctoral student motivation (cf. the work of Devos and others, see Related Work), or his role as both the designer and main implementer of the interventions.

- To answer the informative questions of RQ1 (about the relations between progress, mental health and dropout, see Figure 1) quantitatively, we have used correlation analyses of the burnout, dropout ideation and progress measures taken in the initial questionnaire (using Kendall's $\tau$ and Wilcoxon rank-sum tests, given the non-normality/binary nature of these variables). Further correlation analyses have been performed using partial correlations, represented as Gaussian Graphical Models (GGM, see Epskamp et al., 2018), to understand the bi-variate relations between such (often overlapping) variables, once we control for the other variables. A similar partial correlation analysis has been performed on the quantitative data from the diary exercises, to start exploring how progress relates to other variables (relevant to productivity and mental health) in doctoral students' daily experience. These correlations have been triangulated with a contrast analysis of the qualitative codes comparing a) the initial responses of students with high vs. low burnout (determined via a median cut); b) the initial responses of students that had considered dropping out (vs. those that had not); and c) the diary entries of days that the students had considered with "positive progress" (vs. non-positive progress days). 
- To answer the questions about workshop effectiveness (RQ2), basic inferential statistics (paired t-tests) were drawn of the students' psychological capital before and after each of the workshops, and on the overall dataset. To further explore the variance across individuals of the gains in psychological capital, linear mixed-effects models have been constructed, using small-sample Akaike Information Criterion (AICc, see Hurvich \& Tsai, 1991; Sugiura, 1978) to select the best model, balancing model complexity and prediction error (Zuur et al., 2009), using quantitative variables from the initial questionnaires (burnout, sense of progress, dropout ideation) as markers of individual difference. These quantitative models were triangulated with the effects of the workshops noted spontaneously by students themselves (from the qualitative content analysis). Furthermore, a contrast of the content analysis codes in diary entries by those students that had largest vs. smallest psychological capital increases (via a median cut) was also performed, to further explore what everyday factors or individual differences and habits may be related to well-being gains from this kind of intervention.

- Finally, to understand what aspects of the interventions were most effective and later derive intervention design recommendations (RQ3), linear mixed-effects models were used to ascertain the relative strength of effects in the psychological capital gains of each workshop, while controlling for other individual variables (e.g., initial burnout or perception of one's own progress in the doctorate). Descriptive statistics and an analysis of the codes from the content analysis of post-workshop questionnaires were also triangulated to understand stronger and weaker aspects of the interventions. Further triangulation was done with the unstructured researcher observations about the in-the-moment engagement and reactions of the participants during the workshops.

Ethics and data privacy. This research followed the European Code of Conduct for Research Integrity (ALLEA - All European Academies, 2017), its Estonian counterpart (Centre for Ethics, University of Tartu, 2017), the EU General Data Protection Regulation (GDPR), and the Data protection law of Estonia (Riigi Teataja, 2019). Following TLU's Ethics Committee guidelines, an ethical review was performed by the CEITER project's Ethics Committee (i.e., the local Institutional Review Board IRB, review cases \#0002 and \#0003). The research complies with the regulations and procedures arising from the Personal Data Protection Act. In all workshops, participation was voluntary, participants were asked for their informed consent prior to data collection, and all the data used, in terms of questionnaires and diaries, were gathered anonymously (using an anonymous identification code or nickname for each participant, as mentioned above). All other personally identifiable data have been anonymized before reporting.

\section{RESULTS}

\section{Is the Perception of Progress Related to Doctoral Well-Being AND DROPOUT? (RQ1)}

We correlated students' satisfaction with their own progress (as a simple 1-5 Likert scale question, from very unsatisfied to very satisfied) and the 8-item measure of burnout before the workshops. After testing both measures for normality (using a Shapiro-Wilk test), we found that the burnout measure complied with this assumption, but progress did not (thus, calling for non-parametric tests). Using Kendall's $\tau$ correlation (which has the additional advantage of being more robust to outliers, given our relatively small sample size), we found that pre-workshop respondents' ( $N=78$ students answered this questionnaire) perceived progress and burnout were negatively and significantly correlated $(\tau=-0.35, \mathrm{p}<0.001$, see Figure 4, left). 

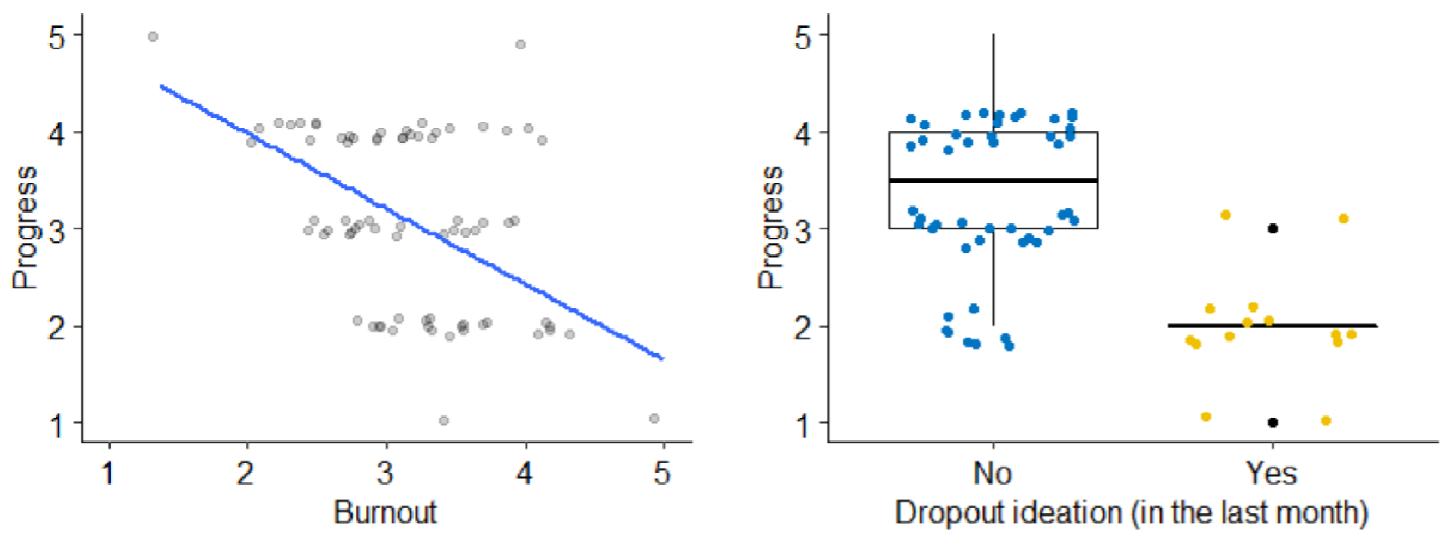

Figure 4. Relationship between burnout measures and self-perceived progress of doctoral students before the workshop (left). Distribution of self-perceived progress for students that had considered dropping out of their studies in the previous month vs. those that had not (right).

A Wilcoxon rank-sum test indicated that the distribution of perceived progress in those students that had considered dropping out was not the same as those that had not considered that $(\mathrm{N}=78$, $\mathrm{W}=1246, \mathrm{p}<0.001)$. A similar Wilcoxon test showed also that the distribution of perceived progress differed significantly (see Figure 4, right) between those students that had considered dropping out in the previous month, and those that had not (a question in the second and later workshops, $\mathrm{N}=64$, $\mathrm{W}=627, \mathrm{p}<0.001)$. These two tests thus suggest an association between dropout ideation and perceived progress.

To further triangulate quantitatively this relationship between progress, burnout (as an emotional well-being variable) and dropout ideation, and start generating hypotheses about the causal or mediational structure between these variables, we can look at the partial correlations of doctoral students' answers before the workshops (represented as a Gaussian Graphical Model, see Figure 5, left). There, we can see that the positive correlation between burnout and dropout ideation (Kendall's $\tau=+0.25$, $\mathrm{p}=0.009)$, turns out not to be statistically significant, once we control for progress. This suggests that progress could be an important causal or mediational factor to both dropout and burnout (although we still cannot know the direction of causality from these tests). A similar analysis of the quantitative variables present in the diary/self-tracking exercise proposed to doctoral students during the later four workshops helps us further understand how perceived progress manifests on a daily basis (see Figure 5, right). We can see that, once we control for the other variables (i.e., through partial correlations), the time spent working on thesis materials is the only significant correlate of progress (as expected). We can also observe that this time spent on dissertation materials is at odds with both the time spent on other work obligations (e.g., teaching, another job, etc.) and the time spent sleeping. While initially this is somewhat expected (there is only so much in a day, and time spent in one task necessarily detracts from the others), the strength of the partial correlations suggests that other work obligations are important obstacles to progress in the dissertation (e.g., for part-time doctoral students). This analysis also suggests that doctoral students often spent time on their thesis at the cost of sleep time: participants reported in the diary entries sleeping an average of 7.3 hours, with $23 \%$ of entries falling below the 7 hours threshold (plus, such self-reports are likely to be overestimations, see Lauderdale et al., 2008). It is worth noting that sleep is a critical element of self-care, and an important factor in the doctoral mental health literature (see, e.g., Marais et al., 2018; McKinzie et al., 2006). Ideally, one would hope that the correlations between sleep and the time spent on the thesis or other work, would be zero. 

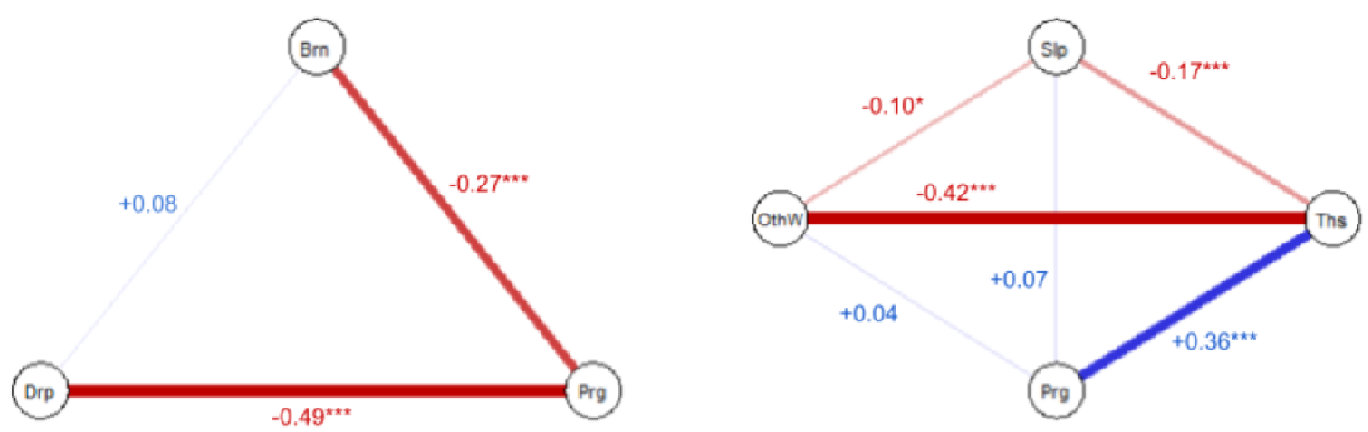

Figure 5. Left: Partial correlations between dropout intentions (Drp), burnout (Brn) and selfperception of progress (Prg) in the initial questionnaires of $\mathrm{N}=78$ doctoral students. Coefficients and p-values calculated using Kendall's method. Right: Partial correlations between time spent sleeping (Slp), time spent doing thesis-related work (Ths) and time spent on other work obligations ( $\mathrm{OthW}$ ), in $\mathrm{N}=310$ diary entries from 46 doctoral students. ${ }^{*} \mathrm{p}<0.05$; $* * \mathrm{p}<0.01, * * * \mathrm{p}<0.001$

Looking at how perceptions of progress differ qualitatively for doctoral students at different levels of emotional well-being, an open coding of the responses given in the pre-workshop questionnaire about particular progress or blockage episodes showed that high-burnout students expressed more often being alone during both progress and blockage episodes. They also mentioned more often blockages due to a lack of knowledge or resources to progress in their $\mathrm{PhD}$ (e.g., "The university does not have any support to research or [accept] more students [...] I spent two months to get an apartment." [Participant21, P21 from now on]; "Lack of team support for data cleaning and analysis, as I don't know how to do it [...] Lack of necessary means" [P57]), or blockages being due to their personal situation ("Three strong blockages due to family losses in a short time." [P30]; "I saw that the birth of my second daughter, the job and the emotional situation did not allow me to find time [for the thesis]." [P61]). High-burnout students also reported emotions of doubt or fear more often, during such blockage episodes ("Fear of advancing without knowing if what you are doing the correct thing" [P19]; "The 'panic' of seeing a work to which you have dedicated lots of hours and effort is rejected and 'dispatched' with a cold comment of 'it does not add anything"' [P23]). On the other hand, low-burnout students more often described blockage situations due to the COVID-19 pandemic and related restrictions (e.g., "I felt blocked during quarantine since I could not advance with the research from home" [P32]; "This year has been a difficult one due to COVID restrictions. I have 2 kids at home, and finding time to concentrate is almost impossible this month" [P78]), and due to issues of lack of focus or exhaustion ("Distractions, in the face of any problem it is very easy to distract oneself with the phone or any other thing. This is emphasized working from home." [P52]; "After a long workday which I insisted on making longer with hours dedicated to the [thesis] introduction." [P64]). Interestingly, low-burnout students also mentioned a larger number (and wider variety) of coping strategies for their productivity challenges (not only about time or task management but also focusing on learning new things, the regularity of their efforts or supervising undergraduate students as a way to be motivated about the thesis topic). Low-burnout students also reported a wider variety and number when asked about relevant indicators of progress in their $\mathrm{PhD}$ (not only emphasizing classic writing/publication outputs, but also creativity, learning new things, collecting data, or conceptualizing the dissertation as a whole).

A similar contrast of the initial qualitative responses of students that had considered dropping out of the doctorate (vs. those that had not), uncovered that students that had considered dropping out also reported more often blockage (and progress) episodes in which they were alone, blockages related to obtaining bad results in their studies (e.g., "I did an experiment related to my main thesis objective, all morning. When I went to take measures in the afternoon I saw the cells were dead, so all the morning's work was wasted." [P35]), or progress episodes related to participating in their scientific com- 
Progress-Oriented Workshops for Doctoral Well-being

munities ("I attended a 10-day summer school and got to know many colleagues doing research on similar topics. We had thought-provoking seminars and workshops." [P12]). As with the case of lowburnout, participants that had not considered dropping out reported more blockage episodes related to lack of focus or exhaustion, and progress episodes related to discussing with others and getting feedback about their work -- from supervisors or others ("Getting some constructive feedback and generating new ideas off the back of it. I was with my supervisor in the academic staff office." [P4]; "Discussions with my supervisors where we were working towards putting together a project which will help me in finalizing my next articles." [P9]). In this case, the reported coping strategies and indicators of progress were not as distinctively different as in the case of high- vs. low-burnout students.

Finally, a content analysis of the diary entries on "good progress" days (those marked with a positive satisfaction value in the Likert scale mentioned above), showed that emotions of happiness, satisfaction, hope or acceptance were disproportionately present (e.g., "I finished processing the samples, I'm happy because they were the first ones I did after a long time" [P38], or "Tomorrow I will analyze the data..., let's hope we'll see a result close to what I believe will happen.” [P35]). On the rest of the days (i.e., neutral or negative satisfaction with progress), doctoral students often reported emotions of fear, frustration or anxiety (e.g., "I've been quite a long time stuck in this point, and I feel frustrated" [P36] or "This makes me very nervous." [P17], or "I have also felt fear and worry that the engineers are very busy and don't want to collaborate with us in the end.” [P57]). This further points towards a qualitative relationship between progress and doctoral students' emotional wellbeing.

\section{Do the PRogRess-OrIENTED INTERVENTIONS IMPROVE PARTICIPANTS' WELL-BEING? (RQ2)}

To understand the immediate effects of the interventions on doctoral students' emotional well-being, we looked at participants' measures of psychological capital (PsyCap) before and after the workshops. In all five workshops, there were positive differences in the average PsyCap score after the workshop. Paired t-tests showed the following statistical significances and effect sizes:

- First workshop (w1, TLU, 2h, face-to-face): non-significant difference $(\mathrm{N}=8, \mathrm{t}=2, \mathrm{df}=7$, $\mathrm{p}=0.09)$, moderate effect size (Cohen's $d=0.54)$.

- Second workshop (w2, UVA, 6h, face-to-face): significant difference $(N=17, t=4, d f=16$, $\mathrm{p}<0.001)$, large effect size (Cohen's $d=1.00)$.

- Third workshop (w3, UVA, 5.5h, online): significant difference $(\mathrm{N}=9, \mathrm{t}=3, \mathrm{df}=8, \mathrm{p}=0.008)$, large effect size (Cohen's $d=1.02$ ).

- Fourth workshop (w4, UVA, 8h, online): significant difference $(\mathrm{N}=14, \mathrm{t}=3, \mathrm{df}=13$, $\mathrm{p}=0.002)$, large effect size (Cohen's $d=0.93)$.

- Fifth workshop (w5, TLU, 8h, online): non-significant difference ( $N=8, t=2, d f=7, p=0.06)$, moderate effect size (Cohen's $d=0.61)$.

We can observe a difference in effect sizes between the workshops held at TLU and UVA (but also in the number of respondents). Later analyses (see below) will delve into whether this difference can be explained by workshop format differences, individual participant differences, or whether there are any other inherent differences due to the country/institution where the workshops took place.

A similar paired t-test taking the five workshops as a whole (in total, $\mathrm{N}=56$ students that responded to both pre- and post-questionnaires) also suggests that participants exited the workshops with significantly higher psychological capital $(\mathrm{t}=6, \mathrm{df}=55, \mathrm{p}<0.001)$, and that the overall size of the effect was large (Cohen's $d=0.83$ ).

Qualitatively, doctoral students mentioned spontaneously effects they had noted during/after attending the workshops (in the post-questionnaires or in the diary entries during the workshop duration). The most frequently mentioned effect of attending the workshops was the students' increased 
awareness of their own progress ("The daily self-tracking helped me see small progress events and this [helped] raise my spirits. [...] during the course's weeks I have been more aware of progress than in all the time before it." [P55]), as well as certain reframing or realizations about their work ("Need to take time off for writing or use time-blocking. Parallel writing with a daytime job does not work." [P70]). Several students also reported a renovated sense of confidence or optimism ("I have survived everything and I will survive [the doctorate]" [P22]).

To understand the individual variance of these benefits and their relation with different student profile covariates (e.g., initial burnout, perceptions of progress or dropout ideation), we explored several linear mixed-effects models (see Table 1), using small-sample AIC (AICc) for model comparison. Assuming individual participants as a random effect, we found that an initial model that only considers time as a fixed-effect predictor (i.e., post vs. pre psychological capital, see Model 1 in Table 1), again shows that there is a significant pre-post effect $(\mu=+0.33$ in PsyCap's 1-6 scale), accounting for $16 \%$ of the variance in the data. Individual differences thus accounted for $84 \%$ of the variance in this model. To start teasing out some of these individual differences, several models were compared, using individual variables of each participant, like their initial perception of progress, burnout or dropout ideation as fixed effects (e.g., Models 2 and 3 in Table 1). The most predictive yet parsimonious of these models (as per their AICc), found a significant dampening effect of the workshop's benefits (in terms of PsyCap) for the students' initial burnout (Model 3 in Table 1). In this model, the fixed effects of the workshop benefit and the individual differences in terms of burnout account for $20 \%$ of the variance, and thus other individual differences account for $80 \%$ of the variance in PsyCap gains.

Table 1. Linear mixed-effect model coefficients and main evaluation metrics, of participant doctoral students' psychological capital, as a function of other individual variables.

\begin{tabular}{|c|c|c|c|}
\hline & \multicolumn{3}{|c|}{ Dependent variable: Positive psychological capital (PsyCap) } \\
\hline Fixed effects & Model 1 & Model 2 & Model 3 \\
\hline Coefficient (std. error) & (pre-post effect only) & (individual covariates) & (more parsimonious) \\
\hline Time, i.e., post vs. pre & $+0.33 * * *(0.05)$ & $+0.34^{* * *}(0.05)$ & $+0.34 * * *(0.05)$ \\
\hline Burnout & & $-0.40^{* *}(0.12)$ & $-0.52 * * *(0.11)$ \\
\hline Progress & & $+0.13(0.09)$ & \\
\hline Dropout ideation & & $-0.10(0.16)$ & \\
\hline Constant/Intercept & $4.40 * * *(0.07)$ & $5.30 * * *(0.57)$ & $6.10 * * *(0.35)$ \\
\hline Observations & 142 & 134 & 134 \\
\hline Log Likelihood & -116 & -101 & -100 \\
\hline Akaike Inf. Crit. & 241 & 215 & 211 \\
\hline Bayesian Inf. Crit. & 253 & 236 & 225 \\
\hline
\end{tabular}

As a further way to qualitatively understand individual differences in the benefits obtained from the workshop throughout its duration, we contrasted the content-analyzed diary entries of those students that most and least benefited from the interventions (in terms of PsyCap). Students that benefited highly from the workshops reported disproportionately being blocked by lack of knowledge, resources or lack of support by their teams and supervisors (e.g., "There's always something, today we could not start the experiments upon which my thesis may be based either." [P43], or "I have felt like 
Progress-Oriented Workshops for Doctoral Well-being

the laughing stock. After 6 and 8 months without contact, not because of my lack of interest, the only response is to ask me whether I know [bibliographic database]" [P53]). They also reported more often being slower or less productive than expected (e.g., "The progress in the dissertation today has been slower and smaller than expected.” [P50]). These high-benefit students also phrased the goals for their next day in a more personal manner ("I want/try/hope/have to do...”). In contrast, students that benefited less from the workshops reported more often being blocked due to lack of motivation or ability to focus (e.g., "Demotivated by lack of progress towards $\mathrm{PhD}$ despite the workload" [P76], or "I started to write the introduction to my article but got bored quickly so I dealt with some other work-related stuff (plans, e-mails etc)." [P69]) as well as feelings of exhaustion or sickness (e.g., "Sick, and anxious due to only working one hour only." [P65]). These participants' progress episodes were more often expressed in terms of sticking to their plans/goals (e.g., "I set three goals which I achieved!" [P69]). Some of these low-benefit students also expressed their daily narratives in ways that suggested an external locus of control ("Read the text that my professor ordered" [P65], or "I had a course and I [was] supposed to read 2 papers and do some critics." [P79]). Notably, these participants also tended to express their goals for the next day in a vague or imprecise manner (e.g., "Continue with my obligations to be done this week. Also, try to advance with the dissertation things." [P26] or "In terms of PhD studies - there's something I need to think about tomorrow." [P72]). This qualitative evidence may suggest that the workshops gave more of a sense of hope, optimism and self-efficacy (part of the PsyCap construct) to students that felt blocked by certain external factors (like lack of resources or support), maybe due to the realization that they are not alone in suffering them (see also the findings for RQ3 below). It also suggests that certain participant states (e.g., lack of motivation or exhaustion, which could be linked to burnout - see the quantitative models mentioned above), as well as beliefs and habits of thinking (vagueness of goals or low sense of agency), may dampen the benefits of these interventions. Nevertheless, these are only exploratory findings that need further confirmatory evidence from future research.

\section{HoW SHOULD WE DESIGN INTERVENTIONS TO FOSTER DOCTORAL PRogress? (RQ3)}

To understand how the different workshop formats influenced the benefits (in terms of PsyCap), we explored additional linear mixed-effects models adding the workshop format (as a single variable, or as differentiated variables like the amount of contact hours, overall length, etc.) as either fixed or random effects. However, these models did not improve on the ones presented in the previous section (as measured by the models' AICc), indicating that, once we take into account the personal variability in terms of, e.g., initial burnout, the effects of the different workshop formats on PsyCap may not be significantly different. A similar conclusion can be drawn for the apparent difference in effect sizes between the workshops at TLU and UVA (see previous section): these can be explained away by individual differences among the participants (e.g., in terms of initial burnout).

To triangulate this finding, we also examined participants' own self-reported opinions after the workshops in a quantitative and qualitative way, to understand potential improvements to the intervention. Quantitatively, participant feedback responses ( $N=64$, see Figure 6) were on average rather positive (all averages over 4 in a 1-5 Likert scale). The first, shorter workshop was generally the worst perceived one, across all questions. The second (face-to-face), fourth and fifth (longer, online) workshops were generally better received than the others. The second and fourth workshops (both multidisciplinary and held in Spain) were also the ones that seemingly would have more effect on the students' behavior (as per the question of whether they would change their practice using the workshop ideas, see the top bars in Figure 6, right). While clarity and the purpose to recommend the workshop to other students were generally rated highest (averages of 4.62 and 4.66 in the 1-5 scale, respectively), the workshops were less successful at inducing behavior change intentions, nor were they unanimously considered useful for participants' personal life (overall averages 4.27 and 4.28, respectively). 

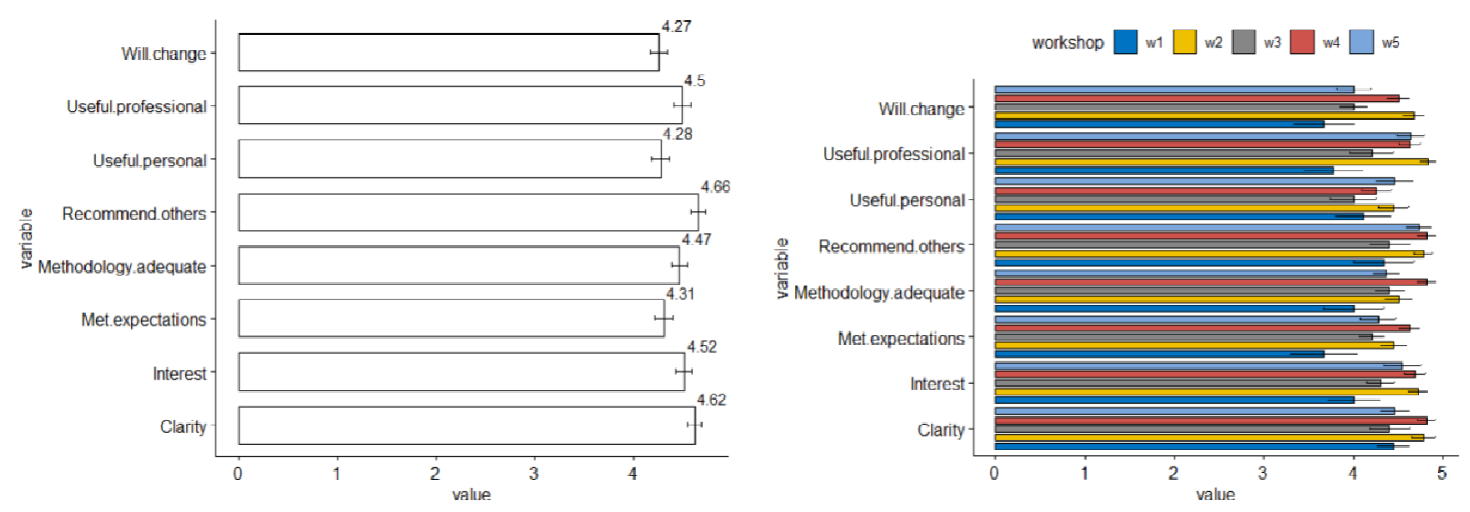

Figure 6. Average and standard error of post-workshop feedback questions. Left: overall values, taking all workshops together. Right: comparison of responses in the different workshops.

Qualitatively, an open coding of the responses to the post-workshop feedback elicited aspects of the workshop format, which in turn led the authors to address and change the workshop format in subsequent iterations (see also the format's temporal evolution in the Methodology):

- The first workshop (one session, $2 \mathrm{~h}$ long, face-to-face) was generally considered too short and with insufficient opportunities to share and collaborate among participants. Participants also noted that further productivity and mental health advice were needed. There were not many mentions of intentions to change everyday practice by participants and, those that did, mostly mentioned starting a journaling practice.

- The second workshop (two sessions, $6 \mathrm{~h}$ in total, face-to-face) garnered much better feedback qualitatively, with many doctoral students intending to change their practice. Most of these intended changes related to concrete productivity techniques mentioned during the workshop (e.g., the "pomodoro technique", see Cirillo, 2006), but also cognitive and emotional reframes were mentioned (e.g., "relativize the importance of the problems I'm facing" [P22]). The productivity module introduced in this workshop was highly valued, with the mental health module also garnering remarks as one of the most useful aspects of the workshop. Still, this format was considered too short, and more concrete mental health tips were demanded by participants.

- Despite incorporating many of the previously mentioned improvements, the third workshop (four online sessions, $6 \mathrm{~h}$ of synchronous work and $2 \mathrm{~h}$ of individual online work - due to the COVID pandemic restrictions in force at the time), had less positive feedback and fewer mentions of practice change intentions after the workshop. The main weakness cited by participants was simply its online/distance nature. Still, the productivity, mental health and progress modules were appreciated as most interesting and useful, by different participants.

- The fourth and fifth workshops shared the same format (four online sessions, $8 \mathrm{~h}$ of synchronous work and about $2 \mathrm{~h}$ of individual asynchronous work). Among the intended practice changes most often mentioned by participants, the adoption of reflection exercises meant to foster appropriation (e.g., the "thesis map" exercise in the last workshop session, see Methods), the continuing of progress-noticing practices like journaling, or particular productivity techniques (like the aforementioned "pomodoro"), were among the most often mentioned change intentions. The simple noticing and celebration of progress were also mentioned by multiple participants (e.g., "Appreciating more finishing the small tasks and assignments" [P76]). Aside from the productivity, mental health and progress practices modules (also appearing in previous workshops), some of the participants mentioned looking at the dashboard with data and models from the group and one's own diary entries as very valuable (e.g., when asked about the most interesting aspect about the workshop: the "analysis 
Progress-Oriented Workshops for Doctoral Well-being

of models to interpret the results of the daily tracking of activities." [P62]). Others noted that the workshop had helped them realize that they were not alone in experiencing the mental health and productivity challenges mentioned (e.g., "[the most interesting aspect was] hearing that I am not the only one experiencing problems and that it is normal" [P69]). Regarding improvable aspects of the workshop, responses were quite varied, or even contradictory (two participants mentioned that more time would be needed, while another one considered it too long). Three participants expressed the desire to have more time to discuss and share experiences with their peers. The most common complaint (voiced by 6 participants out of 27 respondents from these workshops) was the fact that the workshops were online experiences, rather than face-to-face. Nonetheless, other participants commended the teaching methods used and the leveraging of online whiteboard exercises to engage them in such an online format (e.g., "Through the whiteboard exercises you have managed to make it very dynamic and participatory." [P57]). The sparsity and variety of these weaknesses and suggestions signalled that the workshop format was, at this stage, quite appropriately timed (even if minor improvements are always possible).

To triangulate these participant self-reports, the observations made by the research team during the workshop suggest that participants were more engaged (both verbally and non-verbally) and more open to sharing their experience in the face-to-face workshop formats. This may be due to the inherent nature of the online interaction, but also because, in the online workshop, several of the students were attending from their labs or offices where other people were also present (hence preventing them from sharing sensitive material), or performing other tasks in parallel (e.g., driving, receiving requests from other people in their same physical space). Researchers also observed that participants often asked for follow-up interventions (and remarked that they would be interested in participating in more long-term studies of progress). This suggests that these punctual workshop interventions should be followed up by long-term efforts to support doctoral students throughout the dissertation process. Researchers also observed the appearance of domain-specific and stage-specific problems, progress indicators and milestones during the workshops - as well as ad-hoc consultations about particular individual situations.

\section{DISCUSSION}

\section{FINDINGS, LIMITATIONS, AND FUTURE RESEARCH}

The results from our four DBR iterations, as summarized above, point to initial, context-bound answers to our three research questions:

Regarding RQ1 (is the perception of progress related to doctoral well-being and dropout?), the correlations found in our study with doctoral students from two different countries suggest that progress is indeed an important construct related to both dropout ideation and well-being in the doctorate (at least, in terms of burnout). These results confirm prior qualitative and quantitative results in other European countries by Devos, Milicev and colleagues (Devos et al., 2017; Milicev et al., 2020), and generally align with the work of Amabile and Kramer (2011) in the knowledge industry. While causality cannot be inferred from our correlational data, the partial correlations in our study (Figure 4) may suggest that progress is a cause or an important mediator between burnout and dropout (since the correlation between burnout and dropout ideation becomes weak once we control for progress). However, we should not rule out circular relationships between these factors (e.g., the virtuous "progress cycle" observed in Amabile's work or its opposite). The correlations in our diary data and our qualitative content analysis also started teasing out other factors that seem related to everyday perceptions of progress and their impact on well-being and dropout (e.g., the time dedicated to non-dissertation work obligations, long-standing lack of support, or a narrower interpretation of what represents progress in the dissertation). 
Regarding RQ2 (did the progress-oriented interventions improve participants' well-being?), our results show that simple, relatively short interventions had a significant (on average, large) effect on the participants' positive psychological capital. Our results could be compared with, e.g., Barry and colleagues' (2019) mindfulness intervention (which lasted for eight weeks), which had a similar effect size (Cohen's d=1.01). Our results also highlight that there is a large component of individual variation in these benefits. We have already started teasing out components of this individual variation, like the dampening effect of student burnout. Our qualitative analysis provided both (anecdotal) evidence of other effects (like an improved perception of progress) and explored further individual factors (e.g., beliefs or goal-setting habits) that could be related to larger benefits from these interventions.

Finally, our iterative investigation on the design of the intervention itself (RQ3) highlights that longer interventions with practical and participatory components in which students have private spaces to share experiences, are both more effective and better appreciated by students, something that is in line with the findings of recent reviews on social-emotional learning interventions in higher education (Conley, 2015). We can further distil the evidence from our four iterations into budding "design guidelines" for interventions that try to foster doctoral well-being by focusing on progress (see next section).

While our results confirm those of prior related literature, they also have several distinct added values: to the best of our knowledge, it is one of the first multi-country/institution preventive interventions for doctoral well-being. Furthermore, the feasibility and effects of the proposed approach have been tested, not only across two quite different settings but also with different doctoral populations (multi-disciplinary and single-program) and across quite different formats (face-to-face and online), in the very challenging circumstances that the recent COVID-19 pandemic brought. All these aspects make the prospect of generalizing these results to other contexts a hopeful endeavor.

Our evidence, however, and our methodological choices (like the use of DBR, or the dual role of the authors as designers, instructors and researchers/evaluators), also carry several limitations and potential sources of bias with them. Our results and the design guidelines presented in the following section are context-bound. Our findings should also be taken with care given the relatively small number of participants (a common problem in much of the non-survey studies in the field of doctoral education, e.g., Devos et al., 2017). Furthermore, participants themselves may not be representative of the general population of doctoral students: there is a certain over-representation of females, for example (which may be linked to females being more open to talking about mental health issues); also, it is likely that certain types of doctoral students, e.g., with excellent or extremely poor progress (or part-time students with university-unrelated jobs) did not attend our training events. The evidence of benefits from our approach, given our voluntary, convenience sample and the absence of randomization or a control group, also leaves the door open to confounding variables acting into our results (e.g., individual student characteristics, teacher effects, etc.). These confounders include the current COVID-19 pandemic and the lockdown measures (which may have affected the third and later workshops' results). Nevertheless, the fact that the workshop format survived the transformation into an online experience and still showed positive effects, can also be considered a strength of this DBR study. Although we started quantifying the sources of variance from individual differences through the use of mixed-effects models, this issue needs to be more fully addressed in future research. Finally, our measurements did not capture all the breadth of constructs that are common in the doctoral mental health community (we did not measure, e.g., depression or anxiety symptoms), and the phenomenon of attrition was only measured tangentially (through dropout ideation). Especially, the long-term effects of the workshops remain to be studied. Our study did not look at institutional, organizational or cultural factors that may have confounded these results, although the diaries and other qualitative data tried to ameliorate this weakness (and did not find them as a consistent confounder). This selective focus was not due to a belief that these factors are not important (we believe they are, cf. Levecque et al., 2017), but rather due to a conscious choice to aid doctoral stu- 
Progress-Oriented Workshops for Doctoral Well-being

dents most immediately by focusing on factors they have a certain agency over, like their perception of progress (a focus shared by several doctoral studies researchers, e.g., Devos et al., 2017; De Clercq et al., 2021).

Future research in this direction should not only improve the intervention format of progressoriented training and their trialing in other contexts (by other institutions and/or research groups). We will also aim to strengthen the research design of their evaluation, possibly with randomization and a (possibly wait-list) control group. Further attention should be given to teasing out the concept of "progress in the doctorate" itself, untangling its inter-relationships with mental health and attrition constructs, but also addressing the uniqueness of each doctoral candidate and their dissertation process. This will probably require interventions beyond these workshops, where more longitudinal and ecologically valid measures of progress are used (e.g., experience sampling or day reconstruction methods), and the effect of the proposed practices (e.g., journaling or self-tracking) is measured (as suggested by Vekkaila et al., 2014). Given the heterogeneity and uniqueness of doctoral candidates' dissertation work, future research should strive to find not only significant average effects but also uncover individual patterns and dynamics that are practically relevant for trainers and doctoral students themselves (cf. the difference between nomothetic vs. idiographic approaches in psychology, noted by Beltz et al., 2016). Novel methodologies like quantitative ethnography (Shaffer, 2017) or the use of machine learning to automatically mine markers of these constructs and contextual influences in large corpora of such ecologically valid evidence (Cai et al., 2019), should also be on the agenda towards such better support of doctoral students' unique paths to success (cf. the concept of 'singlecase learning analytics' proposed by Prieto et al., 2020).

\section{Designing Progress-Focused INTERVENTIONS IN DoctoraL StUdies}

The workshop formats described and evaluated above are not the only possibility to foster progress in our doctoral students. To encourage other doctoral educators and trainers to develop their own progress-oriented interventions, below we provide several design guidelines stemming from our iterative DBR approach, which we will refine over future iterations:

1. Progress $=$ everyday productivity + mental health. The proposed workshop interventions evolved from a short educational action on the importance of progress (an abstract notion) to more practical tips and grounded reflections about two areas adjacent to making progress and its consequences: productivity and mental health (cf. the overlap between dropout and mental health issues in doctoral populations, noted by González-Betancor \& Dorta-González, 2020). Bringing concrete research- and experience-based techniques, tips and examples that are applicable in students' everyday work (e.g., the appreciation and adoption of the Pomodoro technique and other productivity tips by our participants, or their asking for more concrete mental health tips) can help students see how these two aspects are intimately related.

2. Information is not enough, promote in-context active practices. We should design interventions that go beyond short psycho-educational actions (which often remain abstract and removed from one's experience in-context), encouraging students to use active practices (such as journaling or self-tracking) in their work, even if only as an experiment during the intervention's duration (e.g., keeping the diary for the few days/weeks that the workshop lasts, to see their potential effects). These practices hold the potential of breaking students' pre-existing beliefs about their progress and daily patterns to achieve it. This is consistent with Conley's (2015) observation that interventions that have a supervised practical element have more potent effects than merely psycho-educational ones.

3. Create a safe space to break the mental health taboo. Mental health issues are often related to stigmatization and prejudice (Berry et al., 2021), and are seldom talked about openly. Even if more and more voices are raising the issue (see the studies mentioned in the Related Work), this initial barrier needs to be brought down, through the use of anonymous ques- 
tionnaires, light-hearted ice-breaking exercises (that also point explicitly to rigorous research on the topic), etc.

4. Share experiences to break isolation and perception biases. Related to the previous taboo, many doctoral students have the notion that they are the only individuals that face these struggles. Providing exercises that unearth these biases (e.g., anonymous questionnaires or hands-up questions) enables students to share their struggles, and shows them that they are not alone in facing problems such as "impostor syndrome" (which is very common in doctoral students, e.g., Rosenstein et al., 2020; Sverdlik et al., 2020). This is in line with recent studies suggesting that peer support interventions can benefit doctoral students' subjective well-being (Panayidou \& Priest, 2021).

5. Show me the data, our data. One instructional tool that seemed to capture the students' attention towards realizing the two previous guidelines (as per their comments in the last iteration's workshops), was to show them correlations and data that illustrate the importance of progress and the prevalence of mental health issues like burnout (similar to the ones reported in the Results), using the aggregated data from the group's initial questionnaires and diaries. Simple learning analytics platforms (e.g., the LAPills platform used in the workshops) or online questionnaire tools with visualization capabilities can go a long way in illustrating these issues poignantly. This is a nascent realization in certain areas of healthcare technology design (Flobak et al., 2017) but, to the best of our knowledge, has not been exploited meaningfully in doctoral education and mental health interventions until now.

6. Use technology and exercises to make progress concrete and visible. Many students think of progress in vague terms, and students often think about it in distorted terms (binary thinking, catastrophizing, etc.). The use of dashboards showing self-tracking data (thus making progress and its evolution visible, cf. Shum \& Ferguson, 2012) helped break some of these distortions. Additionally, the inclusion of explicit participatory exercises about what are useful concrete indicators of progress (in different disciplines, and at different granularities) and what are the main milestones on the way to the dissertation (e.g., the "map of the thesis" exercise in the third and later workshops, see Figure 3) may help students have a clearer destination, more coherent reference points, and help them face blockages or setbacks which would impact their motivation.

\section{CONCLUSION}

Doctoral studies remain one of the most challenging and under-served areas of education, and the interlocking problems of attrition and emotional distress still affect hundreds of thousands of our doctoral candidates on a daily basis (see Satinsky et al., 2021; and Taylor, 2021). In this paper, we have proposed the notion of progress in the dissertation as a central concept to address these interlocking problems, and we have iteratively designed and evaluated short interventions that target this notion, to improve students' emotional well-being. While our initial results are encouraging, we still have a long way to go in delving into the idea of doctoral progress, its components and how it can be leveraged to support doctoral student success.

We hope the research presented here sparks a healthy and critical dialogue about how we, as institutions and as supervisors, support our $\mathrm{PhD}$ students in making progress and succeed, while paying attention to their mental health. This may include both structural changes (like facilitating financing possibilities or rehauling whole doctoral programs, see McBrayer et al., 2018), good organizational atmosphere and socialization/community opportunities (cf. Peltonen et al., 2017), but also helping $\mathrm{PhD}$ students change their own everyday practice, as active agents in their development. This was precisely the goal of our interventions, and of the instructional design knowledge that we are starting to accumulate. 


\section{ACKNOWLEDGEMENTS}

This research has received funding from the European Union's Horizon 2020 research and innovation programme under grant agreement No. 669074 (CEITER). It has also received funding from the European Union's Erasmus Plus programme, grant agreement 2019-1-NO01-KA203-060280 (DETEL). The Universidad de Valladolid co-authors acknowledge funding of the European Regional Development Fund and the National Research Agency of the Spanish Ministry of Science, Innovation and Universities, under project grant TIN2017-85179-C3-2-R (SmartLET), and PID2020112584RB-C32, the European Regional Development Fund and the Regional Government of Castile and Leon, under project grant VA257P18.

\section{REFERENCES}

ALLEA - All European Academies. (2017). The European Code of Conduct for Research Integrity (Revised Edition). https://www.allea.org/wp-content/uploads/2017/05/ALLEA-European-Code-of-Conduct-for-ResearchIntegrity-2017.pdf

Amabile, T., \& Kramer, S. (2011). The progress principle: Using small wins to ignite joy, engagement, and creativity at work. Harvard Business Press.

Anderson, T., \& Shattuck, J. (2012). Design-based research: A decade of progress in education research? Educational Researcher, 41(1), 16-25.

Bair, C. R., \& Haworth, J. G. (2004). Doctoral student attrition and persistence: A meta-synthesis of research. In Higher education: Handbook of theory and research (pp. 481-534). Springer.

Barab, S., \& Squire, K. (2004). Design-Based Research: Putting a Stake in the Ground. Journal of the Learning Sciences, 13(1), 1-14.

Barry, K. M., Woods, M., Martin, A., Stirling, C., \& Warnecke, E. (2019). A randomized controlled trial of the effects of mindfulness practice on doctoral candidate psychological status. Journal of American College Health, 67(4), 299-307.

Barry, K. M., Woods, M., Warnecke, E., Stirling, C., \& Martin, A. (2018). Psychological health of doctoral candidates, study-related challenges and perceived performance. Higher Education Research \& Development, 37(3), 468-483.

Bauer, J. L. (2016). Personality factors, self-care, and perceived stress levels on counselor education and counseling psychology doctoral students $[\mathrm{PhD}$ Thesis]. Western Michigan University.

Beltz, A. M., Wright, A. G. C., Sprague, B. N., \& Molenaar, P. C. M. (2016). Bridging the Nomothetic and Idiographic Approaches to the Analysis of Clinical Data. Assessment, 23(4), 447-458. https://doi.org/10.1177/1073191116648209

Bernstein, E. E., LeBlanc, N. J., Bentley, K. H., Barreira, P. J., \& McNally, R. J. (2020). A Single-Session Workshop to Enhance Emotional Awareness and Emotion Regulation for Graduate Students: A Pilot Study. Cognitive and Behavioral Practice, S1077722920301127. https://doi.org/10.1016/j.cbpra.2020.09.008

Berry, C., Niven, J. E., Chapman, L. A., Valeix, S., Roberts, P. E., \& Hazell, C. M. (2021). A mixed-methods investigation of mental health stigma, absenteeism and presenteeism among UK postgraduate researchers. Studies in Graduate and Postdoctoral Education, 12(1), 145-170. https://doi.org/10.1108/SGPE-06-2020-0034

Bodily, R., \& Verbert, K. (2017). Review of Research on Student-Facing Learning Analytics Dashboards and Educational Recommender Systems. IEEE Transactions on Learning Technologies, 10(4), 405-418. https://doi.org/10.1109/TLT.2017.2740172

Braun, V., \& Clarke, V. (2019). Novel insights into patients' life-worlds: The value of qualitative research. The Lancet Psychiatry, 6(9), 720-721. https://doi.org/10.1016/S2215-0366(19)30296-2

Byrom, N. C., Dinu, L., Kirkman, A., \& Hughes, G. (2020). Predicting stress and mental well-being among doctoral researchers. Journal of Mental Health, 1-9. 
Cai, Z., Siebert-Evenstone, A., Eagan, B., Shaffer, D. W., Hu, X., \& Graesser, A. C. (2019). nCoder+: A Semantic Tool for Improving Recall of nCoder Coding. International Conference on Quantitative Ethnography, 41-54.

Centre for Ethics, University of Tartu. (2017). Estonian Code of Conduct for Research Integrity.

Cirillo, F. (2006). The pomodoro technique (the pomodoro). Agile Processes in Software Engineering And, 54(2), 35.

Cobb, P., Confrey, J., diSessa, A., Lehrer, R., \& Schauble, L. (2003). Design Experiments in Educational Research. Educational Researcher, 32(1), 9-13.

Colon, T. L. (2012). From cohort to dissertation completion: A grounded study of doctoral program completers [PhD Thesis]. Cambridge College.

Conley, C. S. (2015). SEL in higher education. In Handbook of social and emotional learning: Research and practice (pp. 197-212).

Cornér, S., Löfström, E., Pyhältö, K., \& others. (2017). The relationship between doctoral students' perceptions of supervision and burnout. International Journal of Doctoral Studies.

Creswell, J. W. (2009). Research design: Qualitative, quantitative, and mixed methods approaches. Sage.

De Clercq, M., Frenay, M., Azzi, A., Klein, O., \& Galand, B. (2021). All You Need is Self-Determination: Investigation of PhD Students' Motivation Profiles and Their Impact on the Doctoral Completion Process. International Journal of Doctoral Studies, 16, 189-209. https://doi.org/10.28945/4702

Devine, K., \& Hunter, K. (2016). Doctoral Students' Emotional Exhaustion and Intentions to Leave Academia. International Journal of Doctoral Studies, 11, 035-061. https://doi.org/10.28945/3396

Devos, C., Boudrenghien, G., Van der Linden, N., Azzi, A., Frenay, M., Galand, B., \& Klein, O. (2017). Doctoral students' experiences leading to completion or attrition: A matter of sense, progress and distress. European Journal of Psychology of Education, 32(1), 61-77.

Epskamp, S., Waldorp, L. J., Mõttus, R., \& Borsboom, D. (2018). The Gaussian Graphical Model in CrossSectional and Time-Series Data. Multivariate Behavioral Research, 53(4), 453-480. https://doi.org/10.1080/00273171.2018.1454823

Evans, T. M., Bira, L., Gastelum, J. B., Weiss, L. T., \& Vanderford, N. L. (2018). Evidence for a mental health crisis in graduate education. Nature Biotechnology, 36(3), 282-284.

Flobak, E., Guribye, F., Jensen, D. A., \& Lundervold, A. J. (2017). Designing data-driven interventions for mental health care. Proceedings of the 11th EAI International Conference on Pervasive Computing Technologies for Healthcare, 423-426.

González-Betancor, S. M., \& Dorta-González, P. (2020). Risk of Interruption of Doctoral Studies and Mental Health in PhD Students. Mathematics, 8(10), 1695.

Greene, J. C., Caracelli, V. J., \& Graham, W. F. (1989). Toward a conceptual framework for mixed-method evaluation designs. Educational Evaluation and Policy Analysis, 11(3), 255-274.

Hanson, J., Loose, W., \& Reveles, U. (2020). A Qualitative Case Study of All-but-Dissertation Students at Risk for Dissertation Noncompletion: A New Model for Supporting Candidates to Doctoral Completion. Journal of College Student Retention: Research, Theory \& Practice, 1521025120910714.

Hardre, P. L., Liao, L., Dorri, Y., \& Beeson Stoesz, M. (2019). Modeling American Graduate Students' Perceptions Predicting Dropout Intentions. International Journal of Doctoral Studies, 14, 105-132. https://doi.org/10.28945/4161

Hish, A. J., Nagy, G. A., Fang, C. M., Kelley, L., Nicchitta, C. V., Dzirasa, K., \& Rosenthal, M. Z. (2020). Acceptability and Perceived Effectiveness of Approaches to Support Biomedical Doctoral Student Wellness: One Size Doesn't Fit All. International Journal of Doctoral Studies, 15, 653-684. https://doi.org/10.28945/4669

Hsieh, H. -f., \& Shannon, S. E. (2005). Three approaches to qualitative content analysis. Qualitative Health Research, 15(9), 1277-1288. 
Progress-Oriented Workshops for Doctoral Well-being

Hurvich, C. M., \& Tsai, C.-L. (1991). Bias of the corrected AIC criterion for underfitted regression and time series models. Biometrika, 78(3), 499-509.

Jackman, P. C., Jacobs, L., Hawkins, R. M., \& Sisson, K. (2021). Mental health and psychological well-being in the early stages of doctoral study: A systematic review. European Journal of Higher Education, 1-21. https://doi.org/10.1080/21568235.2021.1939752

Johnson, R. B. (2017). Dialectical Pluralism: A Metaparadigm Whose Time Has Come. Journal of Mixed Methods Research, 11(2), 156-173. https://doi.org/10.1177/1558689815607692

Kitto, K., Lupton, M., Davis, K., \& Waters, Z. (2017). Designing for student-facing learning analytics. Australasian Journal of Educational Technology, 33(5). https://doi.org/10.14742/ajet.3607

Lauderdale, D. S., Knutson, K. L., Yan, L. L., Liu, K., \& Rathouz, P. J. (2008). Self-Reported and Measured Sleep Duration: How Similar Are They? Epidemiology, 19(6), 838-845. https://doi.org/10.1097/EDE.0b013e318187a7b0

Levecque, K., Anseel, F., Beuckelaer, A. D., Heyden, J. V. der, \& Gisle, L. (2017). Work organization and mental health problems in PhD students. Research Policy, 46(4), 868-879. https://doi.org/10.1016/j.respol.2017.02.008

Litalien, D., \& Guay, F. (2015). Dropout intentions in PhD studies: A comprehensive model based on interpersonal relationships and motivational resources. Contemporary Educational Psychology, 41, 218-231.

Liu, C., Wang, L., Qi, R., Wang, W., Jia, S., Shang, D., Shao, Y., Yu, M., Zhu, X., Yan, S., \& others. (2019). Prevalence and associated factors of depression and anxiety among doctoral students: The mediating effect of mentoring relationships on the association between research self-efficacy and depression/anxiety. Psychology Research and Behavior Management, 12, 195.

Lo, C. K., Hew, K. F., \& Chen, G. (2017). Toward a set of design principles for mathematics flipped classrooms: A synthesis of research in mathematics education. Educational Research Review, 22, 50-73.

Lorenz, T., Beer, C., Pütz, J., \& Heinitz, K. (2016). Measuring psychological capital: Construction and validation of the compound PsyCap scale (CPC-12). PloS One, 11(4).

Luthans, F., Avolio, B. J., Avey, J. B., \& Norman, S. M. (2007). Positive psychological capital: Measurement and relationship with performance and satisfaction. Personnel Psychology, 60(3), 541-572.

Luthans, F., \& Youssef-Morgan, C. M. (2017). Psychological Capital: An Evidence-Based Positive Approach. Annual Review of Organizational Psychology and Organizational Behavior, 4(1), 339-366. https://doi.org/10.1146/annurev-orgpsych-032516-113324

Mackie, S. A., \& Bates, G. W. (2018). Contribution of the doctoral education environment to PhD candidates' mental health problems: A scoping review. Higher Education Research \& Development, 0(0), 1-14. https://doi.org/10.1080/07294360.2018.1556620

Marais, G. A., Shankland, R., Haag, P., Fiault, R., \& Juniper, B. (2018). A Survey and a Positive Psychology Intervention on French PhD Student Well-being. International Journal of Doctoral Studies, 13, 109-138.

McBrayer, J. S., Melton, T. D., Calhoun, D. W., Dunbar, M., \& Tolman, S. (2018). The Correlation between SelfEfficacy and Time to Degree Completion of Educational Leadership Doctoral Students. International Journal of Doctoral Studies, 13, 413-439. https://doi.org/10.28945/4138

McKinzie, C., Burgoon, E., Altamura, V., \& Bishop, C. (2006). Exploring the effect of stress on mood, selfesteem, and daily habits with psychology graduate students. Psychological Reports, 99(2), 439-448.

Mertens, D. M. (2012). What Comes First? The Paradigm or the Approach? Journal of Mixed Methods Research, 6(4), 255-257. https://doi.org/10.1177/1558689812461574

Miles, M. B., \& Huberman, M. (1994). Qualitative Data Analysis: An Expanded Sourcebook. Sage Publications.

Milicev, J., Biello, S., \& Gardani, M. (2020). Evaluating Mental Health and Well-being of Postgraduate Researchers: Prevalence and Contributing Factors. PsyArXiv. https://doi.org/10.31234/osf.io/k92hq 
Myers, S. B., Sweeney, A. C., Popick, V., Wesley, K., Bordfeld, A., \& Fingerhut, R. (2012). Self-care practices and perceived stress levels among psychology graduate students. Training and Education in Professional Psychology, 6(1), 55.

Panayidou, F., \& Priest, B. (2021). Enhancing postgraduate researcher well-being through support groups. Studies in Graduate and Postdoctoral Education, 12(1), 42-57. https://doi.org/10.1108/SGPE-06-2020-0038

Peltonen, J. A., Vekkaila, J., Rautio, P., Haverinen, K., \& Pyhältö, K. (2017). Doctoral Students' Social Support Profiles and Their Relationship to Burnout, Drop-Out Intentions, and Time to Candidacy. International Journal of Doctoral Studies, 12, 157-173. https://doi.org/10.28945/3792

Posner, K., Brown, G. K., Stanley, B., Brent, D. A., Yershova, K. V., Oquendo, M. A., Currier, G. W., Melvin, G. A., Greenhill, L., Shen, S., \& Mann, J. J. (2011). The Columbia-Suicide Severity Rating Scale: Initial Validity and Internal Consistency Findings From Three Multisite Studies With Adolescents and Adults. American Journal of Psychiatry, 168(12), 1266-1277. https://doi.org/10.1176/appi.ajp.2011.10111704

Prieto, L. P., Rodríguez-Triana, M. J., Ley, T., \& Eagan, B. (2020). The Value of Epistemic Network Analysis in Single-Case Learning Analytics: A Case Study in Lifelong Learning. In International Conference on Quantitative Ethnography (ICQE20). Springer.

Richardson, C. M., Trusty, W. T., \& George, K. A. (2020). Trainee wellness: Self-critical perfectionism, selfcompassion, depression, and burnout among doctoral trainees in psychology. Counselling Psychology Quarterly, 33(2), 187-198.

Riigi Teataja. (2019). Personal Data Protection Act-Riigi Teataja. https://www.riigiteataja.ee/en/eli/ee/Riigikogu/act/523012019001/consolide

Rockinson-Szapkiw, A. (2019). Toward Understanding Factors Salient to Doctoral Students' Persistence: The Development and Preliminary Validation of the Doctoral Academic-Family Integration Inventory. International Journal of Doctoral Studies, 14, 237-258. https://doi.org/10.28945/4248

Rosenstein, A., Raghu, A., \& Porter, L. (2020). Identifying the Prevalence of the Impostor Phenomenon Among Computer Science Students. Proceedings of the 51 st ACM Technical Symposium on Computer Science Education, 30-36. https://doi.org/10.1145/3328778.3366815

Satinsky, E. N., Kimura, T., Kiang, M. V., Abebe, R., Cunningham, S., Lee, H., Lin, X., Liu, C. H., Rudan, I., Sen, S., Tomlinson, M., Yaver, M., \& Tsai, A. C. (2021). Systematic review and meta-analysis of depression, anxiety, and suicidal ideation among Ph.D. students. Scientific Reports, 11(1), 14370. https://doi.org/10.1038/s41598-021-93687-7

Shaffer, D. W. (2017). Quantitative ethnography. Lulu. com.

Shum, S. B., \& Ferguson, R. (2012). Social learning analytics. Journal of Educational Technology \& Society, 15(3), 326.

Sinclair, M. (2004). The pedagogy of "good" PhD supervision: A national cross-disciplinary investigation of PhD supervision. Department of Education, Science and Training Canberra.

Smith, R. L., Maroney, K., Nelson, K. W., Abel, A. L., \& Abel, H. S. (2006). Doctoral programs: Changing high rates of attrition. The Journal of Humanistic Counseling, Education and Development, 45(1), 17-31.

Sorrel, M. A., Martínez-Huertas, J. Á., \& Arconada, M. (2020). It Must have been Burnout: Prevalence and Related Factors among Spanish PhD Students. The Spanish Journal of Psychology, 23, e29. https://doi.org/10.1017/SJP.2020.31

Sugiura, N. (1978). Further analysts of the data by Akaike's Information Criterion and the finite corrections. Communications in Statistics-Theory and Methods, 7(1), 13-26.

Sverdlik, A., C. Hall, N., \& McAlpine, L. (2020). PhD Imposter Syndrome: Exploring Antecedents, Consequences, and Implications for Doctoral Well-Being. International Journal of Doctoral Studies, 15, 737-758. https://doi.org/10.28945/4670

Sverdlik, A., Hall, N. C., McAlpine, L., \& Hubbard, K. (2018). The PhD experience: A review of the factors influencing doctoral students' completion, achievement, and well-being. International Journal of Doctoral Studies, 13, 361-388. https://doi.org/10.28945/4113 
Progress-Oriented Workshops for Doctoral Well-being

Taylor, S. (2021). Towards Describing the Global Doctoral Landscape. UK Council for Graduate Education. http://www.ukcge.ac.uk/article/towards-global-doctoral-landscape-475.aspx

Terrell, S. R., Snyder, M. M., Dringus, L. P., \& Maddrey, E. (2012). A grounded theory of connectivity and persistence in a limited residency doctoral program. Qualitative Report, 17, 62.

Vekkaila, J., Pyhältö, K., \& Lonka, K. (2014). Engaging and disengaging doctoral experiences in the behavioural sciences. International Journal for Researcher Development, 5(1), 33-55.

Wollast, R., Boudrenghien, G., Van der Linden, N., Galand, B., Roland, N., Devos, C., De Clercq, M., Klein, O., Azzi, A., \& Frenay, M. (2018). Who are the doctoral students who drop out? Factors associated with the rate of doctoral degree completion in universities. International Journal of Higher Education, 7(4), 143-156.

Zuur, A., Ieno, E. N., Walker, N., Saveliev, A. A., \& Smith, G. M. (2009). Mixed effects models and extensions in ecology with R. Springer Science \& Business Media. 